\title{
AS TECNOLOGIAS DA INFORMAÇÃO E COMUNICAÇÃO E A EDUCAÇÃO FÍSICA ESCOLAR: A REALIDADE DE PROFESSORES DA REDE PÚBLICA MUNICIPAL DE FORTALEZA
}

\author{
THE INFORMATION AND COMMUNICATION TECHONOLOGY AND SCHOLAR PHYSICAL \\ EDUCATION: THE REALITY OF THE PUBLIC EDUCATION \\ TEACHERS OF FORTALEZA
}

\section{TECNOLOGÍAS DE LA INFORMACIÓN Y LA COMUNICACIÓN Y LA EDUCACIÓN FÍSICA ESCOLAR: LA REALIDAD DE LOS PROFESORES DE LA RED PÚBLICA DE FORTALEZA}

\author{
Aline Lima Torres ${ }^{1}$ \\ Mabelle Maia Mota ${ }^{2}$ \\ Heraldo Simões Ferreira ${ }^{3}$ \\ Aline Fernanda Ferreira ${ }^{4}$ \\ Suraya Cristina Darido ${ }^{5}$
}

RESUMO: Observa-se um crescente interesse científico em pesquisas sobre o uso das Tecnologias da Informação e Comunicação - TICs no universo da Educação Física escolar. Assim sendo, o presente estudo objetivou verificar o uso delas, especificamente no que concerne ao uso dos computadores pelos professores da rede pública municipal de ensino da cidade de Fortaleza-CE. Participaram do estudo 32 professores. Os dados foram coletados por meio de um questionário semiestruturado composto por questões mistas a respeito do uso das TICs nas aulas de Educação Física. Os dados obtidos foram analisados por estatística descritiva e expressos em gráficos e tabelas. Também foi realizada uma análise interpretativa das questões abertas como forma de compreender o pensamento do grupo pesquisado a respeito do uso de computadores nas aulas de Educação Física. Constatou-se que a maioria dos professores raramente utiliza o computador em suas aulas e, mesmo aqueles que utilizam o fizeram com pouca frequência no decorrer do ano letivo. Verificou-se que os principais motivos seriam a falta de profissionais nos laboratórios e estrutura física adequada para possibilitar a aplicação das atividades. Tais achados indicam, para a realidade pesquisada, a necessidade de intervenções voltadas à formação continuada e de uma maior atenção à infraestrutura e apoio a esses professores.

PALAVRAS-CHAVE: Tecnologias da Informação e Comunicação. Computador. Educação Física Escolar.

\footnotetext{
${ }^{1}$ Mestra em Educação pela Universidade Estadual do Ceará, UECE, Brasil. Professora de Educação Física do município de Fortaleza, CE, Brasil - E-mail: alinamic@ gmail.com.

${ }^{2}$ Mestra em Educação pela Universidade Estadual do Ceará, UECE, Brasil. Professora de Educação Física da Secretaria Estadual de Educação do Ceará, CE, Brasil - E-mail: mabellemota@ yahoo.com.br.

3 Pós-doutor em Desenvolvimento Humano e Tecnologias pela Universidade Estadual Paulista "Júlio de Mesquita Filho" - Campus de Rio de Claro, UNESP, Brasil. Professor adjunto do Centro de Ciências da Saúde, Universidade Estadual do Ceará, UECE, Fortaleza, CE, Brasil - E-mail: heraldo.simoes@uece.br.

${ }^{4}$ Doutoranda em Desenvolvimento Humano e Tecnologias pela Universidade Estadual Paulista "Júlio de Mesquita Filho" - Campus de Rio Claro, UNESP, Brasil - E-mail: alinandafe@ hotmail.com.

${ }^{5}$ Doutora em Psicologia Escolar e do Desenvolvimento Humano pela Universidade de São Paulo, USP, Brasil. Professora assistente doutora no Departamento de Educação Física da Universidade Estadual Paulista "Júlio de Mesquita Filho" - Campus de Rio Claro, UNESP, Brasil - E-mail: surayacd @ rc.unesp.br.
}

Recebido em: 14/09/2015 - Aprovado em: 14/01/2016.

\begin{tabular}{l|l|l|l|l|l|l} 
(C) ETD -Educ. Temat. Digit. & Campinas, SP & v.18 & n.1 & p.198-214 & jan./abr. 2016 & ISSN 1676-2592
\end{tabular}


ABSTRACT: It's observed an increasing scientific interest on research about the use of Information and Communication Technology-ICT in the universe of scholar Physical Education. Thus, this original article has as an objective verify the use of it, specifically regarding the use of computers by the teachers of the public education of the city of Fortaleza-CE. Thirty two teachers participated in the study. The data were collected through a semi structured questionnaire compounded for mixed questions about the use of ICT in the physical education classes. The collected data were analyzed by descriptive statistics and expressed by graphics and charts. Also was realized a analysis of the open questions like a way of understanding the thoughts of the research group about the use of computers in the physical education classes. It was discovered that most of the teachers rarely uses the computer in their classes and, even those who use, made it with low frequency over the school year. It was verified that the principal reasons would be the lack of teachers in the laboratories and suitable physical structure to enable the application of the activities. These facts indicate, for the researched reality, the need of interventions aimed at continuing education and a greater attention about the infrastructure and support to these teachers.

KEYWORDS: Information and Comunication Technology. Computer. Scholar Physical Education.

RESUMEN: No ha habido un creciente interés en la investigación sobre el uso de Tecnologías de Información y Comunicación, TIC en la Educación Física Escolar, por lo tanto, este estudio tuvo como objetivo verificar el uso de estos, específicamente con respecto al uso de las computadoras por los profesores de las escuelas públicas municipais en Fortaleza-CE. Los participantes del estudio fueron 32 profesores. Los datos fueron recolectados a partir de un cuestionario semi-estructurado con preguntas variadas sobre el uso de las TIC en las clases de educación física. Los datos se analizaron mediante estadística descriptiva y se expresan en gráficos y tablas. También se realizó un análisis de las preguntas abiertas con el fin de entender el pensamiento del grupo investigado en el uso de las computadoras en las clases de educación física. Se encontró que la mayoría de los profesores rara vez utilizan la computadora en sus clases, y incluso aquellos que utilizan, lo hizo con poca frecuencia durante el año escolar. Se encontró que la razón principal sería la falta de laboratorios profesionales y estructura física adecuada para permitir la implementación de actividades. Estos resultados indican la necesidad de una mayor atención a la infraestructura y el apoyo a los profesores.

PALABRAS CLAVE: Tecnologías de la Comunicación y Información. Informática. Educación Física escolar.

\section{INTRODUÇÃO}

Atualmente, há um avanço quanto ao uso das tecnologias, em especial à utilização dos computadores como meio para facilitar e dinamizar o processo de ensino-aprendizagem. Nesse sentido, a Educação Física, na qualidade disciplina curricular, também deve estar atenta a esse novo panorama educacional. Para tanto, faz-se necessária uma estrutura que possibilite o uso dessas tecnologias, assim como a iniciativa do professor de colocá-las em ação.

O desenvolvimento tecnológico ocorre sem precedentes na história da humanidade. Ao se tratar de tecnologias para a educação, especificamente, espera-se que sejam úteis para o que se propõem: possibilitar a professores e alunos condições favoráveis para alcançar os objetivos educacionais traçados (BIANCHI; PIRES; VANZIN, 2008).

O termo TICs representa a aquisição, o armazenamento e a distribuição de informações por intermédio de equipamentos eletrônicos e digitais (rádio, televisão, telefone e computadores, entre outros). Trata-se da fusão de diversas tecnologias voltadas para a informação (informática) com as tecnologias da comunicação (telecomunicações e mídias eletrônicas) (BRASIL, 2009?). 
Quando essas tecnologias são usadas para fins educativos no intuito de apoio, melhoria da aprendizagem dos alunos e desenvolvimento de ambientes propícios à aprendizagem pode-se considerá-las um subdomínio da Tecnologia Educativa (MIRANDA, 2007). Compreender as diferentes formas de representação e comunicação favorecidas pelas tecnologias disponíveis na escola, bem como criar dinâmicas que permitam estabelecer o diálogo entre as formas de linguagem das mídias, são desafios para a educação atual (BRASIL, 2009?).

Miranda (2007) aponta em seu trabalho que a falta de recursos das escolas e de formação dos professores são os principais obstáculos para o uso das tecnologias nas práticas pedagógicas. Além desses, Ferreira (2014) acrescenta os problemas na implementação e manutenção dos equipamentos advindos de programas governamentais e a necessidade de mudança na organização da escola, e da concepção de ensino-aprendizagem das instituições.

Melo e Branco (2011) afirmam que a escola não pode ficar alheia às mudanças influenciadas pelas tecnologias, visto que um dos papéis dessa instituição é desenvolver indivíduos autônomos, propiciando momentos de reflexão sobre os mais diversos assuntos, assim como assimilar e questionar as inúmeras informações veiculadas diariamente. Tal ação não é específica de uma ou outra disciplina, tendo a Educação Física assim sua responsabilidade nesse processo.

Segundo Darido (2012), a Educação Física escolar é uma disciplina que apresenta e permite ao aluno integrar-se na cultura corporal de movimento, com a intenção de formar cidadãos que irão produzi-la, reproduzi-la e transformá-la. Ela permite a experimentação e instrumentaliza o aluno para usufruir de danças, jogos, esportes, lutas e ginástica de forma crítica e em benefício da melhoria da qualidade de vida. O conhecimento produzido e divulgado nas diversas mídias sobre essas grandes temáticas é incomensurável, podendo ser discutido/vivenciado de várias formas dentro da disciplina de Educação Física escolar, inclusive fazendo uso das TICs para tal.

Os estudos encontrados na literatura mostram que as TICs são utilizadas nas aulas de Educação Física como estratégia para instigar os alunos a debates, para ensinar os esquemas técnicos e táticos dos esportes e para outras ilustrações do conteúdo, discussão de temas atuais, para pesquisa do professor (aulas, materiais, discussões), produção e visualização de vídeos, curtas-metragens, jornais sobre temas específicos, criação de blogs, entre outros (BUTRICO; KORSAKAS, 2006; BETTI, 2010; MELO; BRANCO, 2011; SILVA, 2012).

Para Camilo e Betti (2010, p. 134), é papel da escola e, nesse contexto, da Educação Física escolar, "dar respaldo ao aluno em suas escolhas sobre como se relacionar com essas mídias e, portanto, elas precisam ser reconhecidas como meios e conteúdos de extrema relevância no currículo escolar".

Dessa forma, as TICs podem aparecer como recurso importante nas ações pedagógicas do professor. Este terá um papel problematizador a fim de criar situações que despertem nos alunos o senso crítico sobre as informações ali recebidas. Nesse processo, deve-se "aprender por meio delas, com elas e em interação com os diversos contextos, que extrapolam - virtualmente - o ambiente tradicional de ensino" (SENA, 2011, p. 9). 
São muitos os recursos tecnológicos possíveis de serem utilizados nas aulas de Educação Física. Pode-se fazer uso de equipamentos habituais como os de televisão, rádio e fotografia e/ou filmagem, bem como de alguns não tão comuns na escola, como os de jogos digitais. Contudo, é o computador que acaba dominando a instrumentalização didática.

O computador hoje agrega inúmeras funções, permitindo não só a apreciação de vídeos, imagens, textos, mas também a criação e o compartilhamento dos mesmos por meio da internet, ampliando assim o potencial criativo dos alunos. Estratégias como as apontadas nos trabalhos de Bianchi e Pires (2010), com o uso de blogs, assim como a realizada por Ferreira e Mota (2014), que fizeram o uso de redes sociais, são bons exemplos.

Os alunos já chegam à escola com um amplo contato com as tecnologias. Incluí-las nas aulas de Educação Física permitiria uma maior conexão e aproximação à linguagem e ao cotidiano deles, possibilitando a discussão e reconstrução de conteúdos baseados nas abordagens feitas por eles e por meio das mídias e/ou que os alunos se interessem, inovando assim as estratégias de ensino e aprendizagem (BIANCHI; PIRES; VANZIN, 2008).

No entanto, ainda conforme Bianchi, Pires e Vanzin (2008), os professores de Educação Física encontram dificuldades em utilizar as TICs em suas aulas e a área pouco tem apresentado inserções sistêmicas nesse campo. Destaca-se também como fatores influenciadores para tal distanciamento: a insuficiência de estratégias políticas de formação inicial e continuada do professorado; o planejamento de propostas educativas qualificadas e críticas na perspectiva das TICs; a deficiência nas condições de trabalho, como estrutura física e material; não serem nativos digitais, portanto a necessidade de fazer cursos para aprender a utilizar as TICs e aproveitar o potencial pedagógico delas; de maneira geral, não têm tempo para frequentar tais cursos, pois muitos têm jornada dupla, tripla, casa e família; encontram vários problemas no ambiente escolar como a desmotivação e desinteresse dos alunos pelas aulas; entre outras dificuldades específicas presentes em cada contexto (BELLONI, 2005; CHANAN; NASCIMENTO; CHANAN, 2006; SILVA, 2011).

Na realidade de Fortaleza, desde 1991, a Prefeitura Municipal, por meio da Secretaria de Educação e Cultura do Município, participa de pesquisas na área de Informática Educativa visando elaborar um programa que possibilite a intervenção das TICs nos processos educativos da região. Formou-se, então, um grupo de técnicos e professores com treinamento específico, os quais realizaram visitas a outros estados, participaram de cursos, seminários e workshops sobre a temática. No ano seguinte foi apresentado ao Ministério da Educação o projeto de um laboratório de informática para fins educativos, projeto esse aprovado com alterações (OLIVEIRA, 2011).

Atualmente, a utilização dos computadores nas escolas da rede pública municipal de Fortaleza é possível por meio do Laboratório de Informática Educativa - LIE$^{6}$, criado pelo Programa Nacional de Informática na Educação - Proinfo. Muitas ações foram desenvolvidas até que fossem implementados os LIEs. A proposta era utilizar o computador como uma

${ }^{6} \mathrm{O}$ MEC nomeou os laboratórios que receberiam os computadores de Laboratórios Escolares de Informática (LEIs). Em Fortaleza, achou-se que o nome mais apropriado seria Laboratório de Informática Educativa (LIE) e até hoje os laboratórios são conhecidos no município como LIEs.

\begin{tabular}{l|l|l|l|l|l|l} 
(C) ETD -Educ. Temat. Digit. & Campinas, SP & v.18 & n.1 & p.198-214 & jan./abr. 2016 & ISSN 1676-2592
\end{tabular} 
ferramenta pedagógica de apoio ao professor nos diversos conteúdos. Para tanto, os professores contavam com o auxílio do responsável pelo laboratório no planejamento das intervenções ${ }^{7}$. Contudo, o que se percebe é que a organização para o acesso, o espaço e a quantidade de computadores ainda é insuficiente.

Em abril de 2013, a nova gestão da Secretaria Municipal de Educação - SME convocou os professores do LIE para retornarem às salas de aula (PMF, 2013), deixando a cargo das escolas a organização de estratégias alternativas para utilização dos laboratórios de informática. Dessa forma, toda a organização, anteriormente implementada, foi desestruturada com a saída dos professores responsáveis pelo laboratório. Desde então, os laboratórios continuam sem profissionais responsáveis, dificultando ainda mais o acesso aos professores para possíveis intervenções didáticas mediadas pelas TICs nas aulas, inclusive na Educação Física.

Refletindo acerca do assunto, formulou-se a seguinte questão investigativa: diante do cenário atual, os professores de Educação Física fazem uso das TICs nas aulas deles? Mais especificamente, utilizam computadores como instrumento pedagógico?

Assim, o objetivo geral do estudo foi verificar com o corpo de professores de Educação Física da rede pública municipal de ensino de Fortaleza de que forma tem se estabelecido o uso das TICs nas aulas deles, no que diz respeito ao uso dos computadores.

\section{MÉTODO}

Foi realizada uma pesquisa de campo descritiva, a qual, segundo Gil (2002), focaliza uma comunidade, não necessariamente geográfica, para captar suas explicações e interpretações a respeito de determinado assunto. O estudo guardou aspectos das abordagens qualitativa e quantitativa ${ }^{8}$. Segundo Neves (1996 apud TERENCE; ESCRIVÃO FILHO, 2006), aliando ambas as abordagens poderemos tanto explicitar passos da pesquisa quanto amenizar a interferência de sua subjetividade nas conclusões obtidas.

A pesquisa concentrou-se no município de Fortaleza, o qual é organizado em sete Secretarias Executivas Regionais (SERs) criadas pela Lei ${ }^{\circ}$. 8.000, de $1^{\circ}$ de janeiro de 1997 , com o propósito de descentralizar a gestão administrativa da cidade. Cada regional é composta por bairros circunvizinhos (Figura 1), com semelhanças em termos de necessidades e problemas. As SERs administram os serviços educacionais à população em cada região por intermédio dos Distritos de Educação.

\footnotetext{
${ }^{7}$ Para maior conhecimento de como aconteciam as intervenções dos LIEs nas escolas, recomenda-se a leitura do estudo de Nascimento et al. (2011).

${ }^{8}$ Atrelada ao paradigma positivista, a abordagem quantitativa tem caráter objetivo e permite a mensuração de opiniões por meio de amostras que podem ser representadas estatisticamente. Já a abordagem qualitativa procura identificar explorar os significados dos fenômenos estudados e as interações que estabelecem, possibilitando novas compreensões sobre a variedade e a profundidade dos fenômenos sociais (TERENCE; ESCRIVÃO FILHO, 2006).
}

\begin{tabular}{l|l|l|l|l|l|l} 
(C) ETD -Educ. Temat. Digit. & Campinas, SP & v.18 & n.1 & p.198-214 & jan./abr. 2016 & ISSN 1676-2592
\end{tabular} 


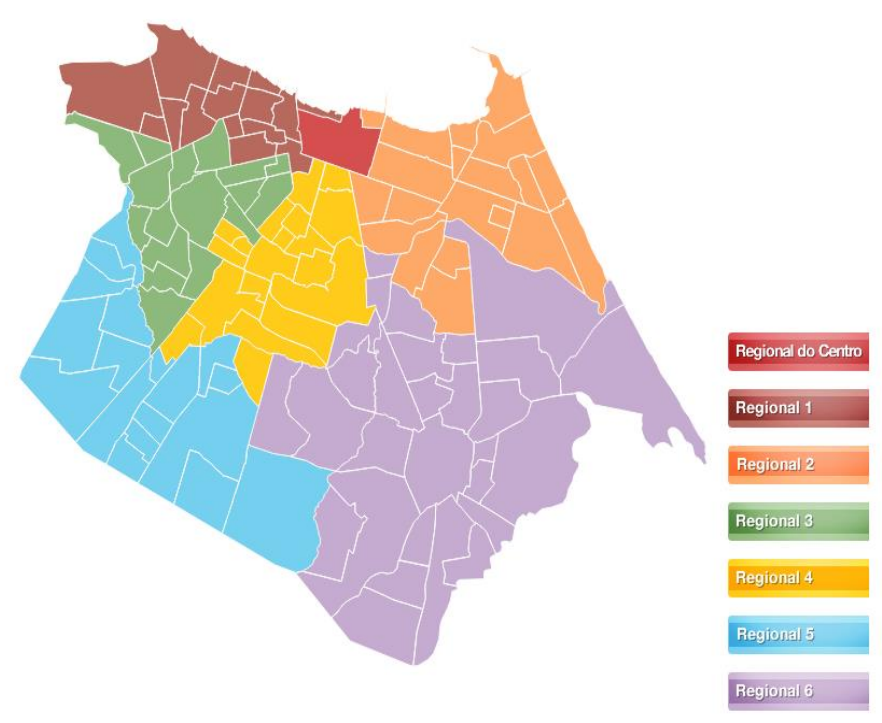

FIGURA 1 - Divisão administrativa da cidade de Fortaleza (PMF, 2014a)

Fonte: Prefeitura Municipal de Fortaleza (PMF, 2014a)

Participaram do estudo os professores de Educação Física da rede municipal de ensino. Foram escolhidos, aleatoriamente, $10 \%$ dos professores efetivos ${ }^{9}$ de cada SER, totalizando 32 professores. Esse número foi estipulado com base nos dados fornecidos pela Secretaria Municipal de Educação (SME) em julho de 2013. Os participantes foram convidados, pessoalmente, via e-mail ou por telefone, pelos pesquisadores, os quais na oportunidade explicaram os objetivos do estudo e a importância do mesmo para a área.

Os dados foram coletados por meio de um questionário semiestruturado ${ }^{10}$, composto de questões objetivas e subjetivas a respeito do uso das TICs, com foco na utilização dos computadores nas aulas de Educação Física, e foram analisados por meio da estatística descritiva $^{11}$ e expressos em gráficos e tabelas. A pesquisa foi realizada na cidade de Fortaleza, no período de agosto a dezembro de 2013.

Os instrumentos foram enviados via $e$-mail ou aplicados pessoalmente, de acordo com a disponibilidade da pesquisadora e dos professores participantes. Foi solicitada a assinatura do Termo de Consentimento Livre e Esclarecido (TCLE) pelos envolvidos e os preceitos éticos da pesquisa com seres humanos foram respeitados.

\footnotetext{
${ }^{9}$ Considera-se professor efetivo aquele aprovado em concurso público para cargo efetivo.

${ }^{10}$ Instrumento de coleta de dados que envolve perguntas abertas e fechadas de acordo com os objetivos propostos pelo estudo e que deve ser respondido sem a presença do pesquisador (THUMS, 2003).

${ }^{11}$ Preocupa-se com a descrição de determinadas características de um grupo, sem, no entanto, tirar conclusões de um grupo maior (SHIGUTI; SHIGUTI, 2006).
}

\begin{tabular}{l|l|l|l|l|l|l} 
(C) ETD -Educ. Temat. Digit. & Campinas, SP & v.18 & n.1 & p.198-214 & jan./abr. 2016 & ISSN 1676-2592
\end{tabular}




\section{RESULTADOS E DISCUSSÃO}

Inicialmente, foi investigado se nas escolas em que os participantes lecionavam existia laboratório de informática. Pelo fato de alguns dos professores trabalharem em mais de uma escola, foi solicitado o relato de todas as realidades. Das 39 instituições relatadas, verificou-se que cinco não possuem laboratório de informática: uma escola na SER I, três na SER II e uma na SER VI. Considerando que a implantação do Proinfo em Fortaleza data de 1994 com as primeiras instalações (OLIVEIRA, 2011), é compreensível que, até o momento da pesquisa (2013), boa parte das escolas estivesse equipada com laboratórios específicos.

Mesmo assim, alguns professores constaram que ainda existem escolas sem laboratório, reforçando a ideia de que perduram as dificuldades relativas à falta de estrutura adequada para possibilitar a intervenção metodológica com o uso dos computadores. Tal fato pode ser compreendido quando, verificando no site da SME, o mapeamento das escolas mostra que, em um total de 464 escolas, apenas 234 possuem laboratório (PMF, 2014b).

Em relação à frequência de utilização do computador pelos professores de Educação Física juntamente com alunos durante o ano letivo, evidenciou-se a baixa frequência dessa ferramenta nas aulas, o que pode ser verificado no Gráfico 1.

GRÁFICO 1 - Frequência da utilização do laboratório de informática nas aulas de Educação Física durante o ano letivo

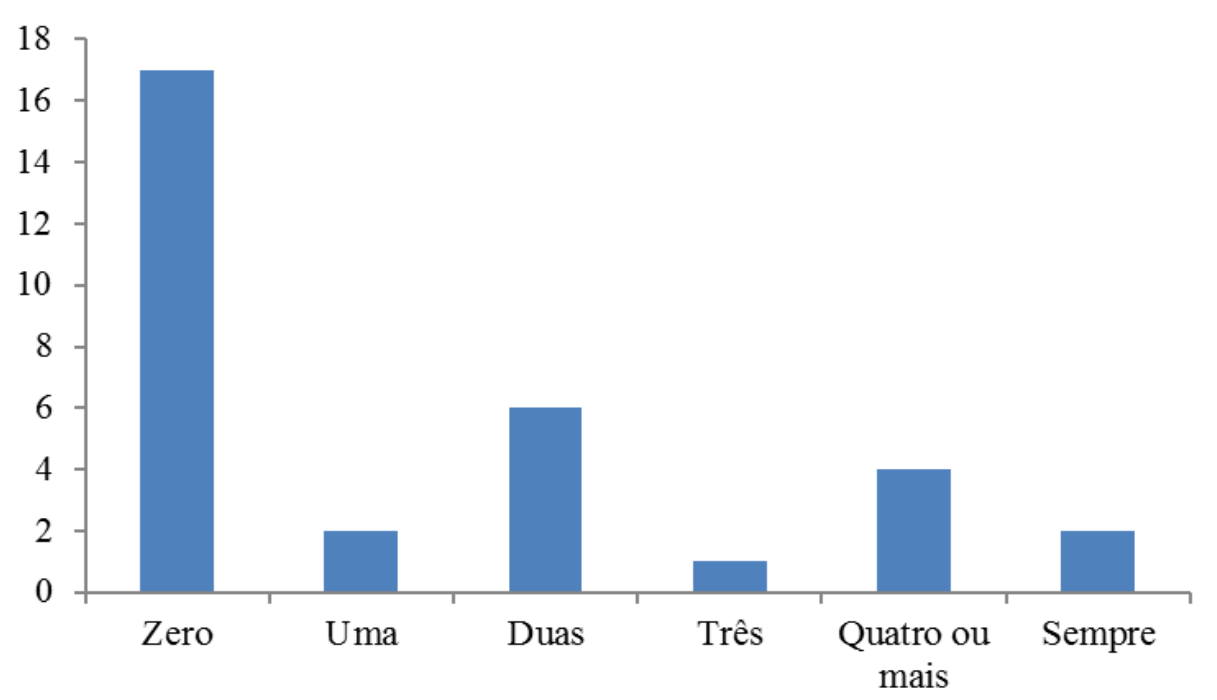

Fonte: Dados da pesquisa

Apesar de o computador estar presente em muitas das esferas da vida social, nas escolas brasileiras o que se tem percebido é a não integração dessa ferramenta tecnológica de forma efetiva. Como aponta o estudo de Brito (2010) em escolas de ensino médio da cidade de Goiânia, o qual evidencia uma pequena parcela de 24 professores do total de 161 propondo-se a utilizarem o LIE em suas aulas. 
Valente (2010) aponta que a educação com as TICs só tem efeito se estiverem integradas ao currículo escolar - quando não se tornam apenas apêndice das aulas ou marketing para a escola. O mesmo autor aponta que é importante o letramento digital dos professores e alunos, ou seja, de "não ser um mero apertador de botões (alfabetizado digital), mas sim ser capaz de usar essas tecnologias em práticas sociais" (VALENTE, 2007, p. 1).

Esse letramento vai além da leitura e da escrita e engloba "o digital (uso das tecnologias digitais), o visual (uso das imagens), o sonoro (uso de sons), o informacional (busca crítica da informação)" (VALENTE, 2007, p. 1), sendo necessário, assim, que os professores estejam capacitados para promover esses múltiplos letramentos e levar os alunos a serem autores, produtores e disseminadores de conhecimento (VALENTE, 2007).

Sobre o computador, Valente (1993) defende que essa é a ferramenta mais presente no cotidiano dos alunos, devendo ser utilizada na escola. Sua inserção exige a mudança do paradigma educacional, promovendo aprendizagem ao invés de ensino, saindo da pedagogia instrucionista para a construcionista, em que é importante que o aluno construa o conhecimento por meio dessa tecnologia.

Procurou-se saber também dos participantes sobre os tipos de aplicações informáticas que utilizavam em suas aulas. Observa-se, pelo Gráfico 2 exposto a seguir, a constatação da baixa utilização dos computadores entre os respondentes, já que metade deles (16) afirmou não utilizar nenhuma aplicação informática. Dentre os que fazem uso, ganham destaque a internet e os recursos multimídia/CD-ROM como as aplicações mais utilizadas. Tais resultados podem transparecer que os poucos que ainda fazem uso dos computadores nos LIEs restrinjam as intervenções com as TICs para pesquisas na internet e apreciação de imagens ou vídeos nos equipamentos multimídia/CD-ROM. Contudo, para comprovar tal afirmação, seria importante o acompanhamento das aulas a fim de verificar de fato quais os procedimentos mais utilizados pelos professores ao recorrer às TICs.

GRÁFICO 2 - Aplicações informáticas utilizadas nas aulas de Educação Física

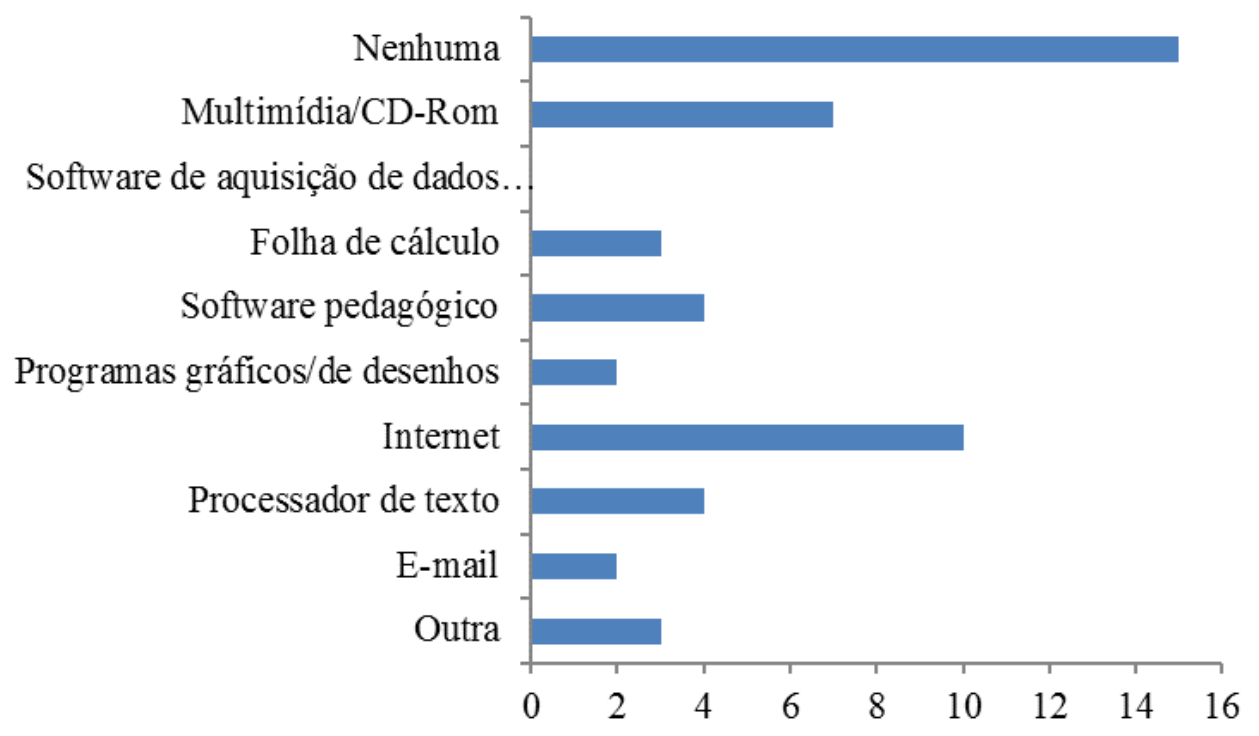

Fonte: Dados da pesquisa. 
Ademais, nos alerta Bianchi, Pires e Vanzin (2008) que, ao utilizar as TICs apenas como um recurso dinamizador das aulas, o professor corre o risco de reduzir seu potencial interativo e inovador. É importante frisar que, antes de tudo, é preciso ter claro os objetivos da inserção das TICs e elucidado qual a contribuição destas para a aprendizagem dos conteúdos escolares.

Pretto (2008) entende a necessidade das tecnologias no espaço escolar, porém, como Belloni (2005), faz crítica ao uso delas como um mero instrumento sem a adoção de uma metodologia em que elas auxiliem de fato no processo ensino-aprendizagem. Nas palavras do autor, as tecnologias "não são complementares, mas essenciais para a nova forma de pensar e produzir conhecimentos. Se coloco as tecnologias na escola como instrumentos, essa escola fica sem futuro, apesar da cara de moderna" (PRETTO, 2008, p. 34).

Considera-se também que a inserção das TICs nas escolas e nas aulas de Educação Física deve ser acompanhada de uma intensa relação delas com a cultura dos alunos, promovendo um ensino contextualizado, que permita uma leitura ampliada e crítica das variadas informações e conhecimentos que podem ser adquiridos por meio das tecnologias e, consequentemente, uma educação para o uso delas (BELLONI, 2005; MORAN, 2011).

É preciso que se compreenda também se houve êxito ou não na aplicação das TICs com os alunos, assim como os motivos que podem ter levado à não utilização desses recursos para o ensino e aprendizagem nas aulas de Educação Física. Por isso, procurou-se averiguar dos participantes que fazem uso das TICs em suas aulas (16) os efeitos positivos e/ou negativos que possam ter surgido diante das intervenções realizadas conforme Tabela 1. Buscou-se compreender também os motivos que levaram os demais professores a não fazerem uso desses recursos em suas aulas como é apresentado na Tabela 2.

TABELA 1 - Pontos positivos e negativos em relação ao uso dos computadores

\begin{tabular}{lc}
\hline Positivos & Quantidade \\
\hline Melhora na aprendizagem e maior interesse do aluno & 17 \\
Incentivo à pesquisa e à informação & 14 \\
Permite o contato e utilização de ferramentas & 02 \\
Melhora do comportamento & 01 \\
Torna a aula mais dinâmica & 01 \\
\hline Negativos & Quantidade \\
\hline Resistência à aula teórica & 01 \\
Objetivo não alcançado devido ao número reduzido de computadores & 01 \\
\hline
\end{tabular}

Fonte: Elaborada pelos autores.

TABELA 2 - Professores que não utilizam os computadores nas aulas

\begin{tabular}{lc}
\hline Motivos & Quantidade \\
\hline Medida adotada pela SME - convocação/retirada de professores do LIE e não & 13 \\
reativação do laboratório com outro profissional & 10 \\
Falta de conhecimento e apoio para a formação e utilização do laboratório & 12 \\
Falta de estrutura adequada para receber e realizar as atividades & 05 \\
Falta de organização para a inclusão da disciplina nas atividades do LIE &
\end{tabular}


Falta de tempo

Fonte: Elaborada pelos autores.

Diante das respostas, percebe-se que os participantes que fazem uso das TICs em suas aulas destacam como maior ponto positivo dessa intervenção uma melhora na aprendizagem e um maior interesse por parte dos alunos. Tal consideração pode ser justificada quando se compreende que essas ferramentas tecnológicas, por fazerem parte da realidade da maioria dos alunos, podem colaborar diretamente com o aprendizado, como representado na fala a seguir:

\begin{abstract}
"A partir de quando comecei a trabalhar com filmes e slides os alunos mostraram-se mais interessados no assunto trabalhado, pois além das explicações, as imagens possibilitam uma compreensão mais significativa do conteúdo. É importante ressaltar a necessidade de preparar um material compatível com a faixa etária para o êxito na utilização destes recursos". (p.15) ${ }^{12}$
\end{abstract}

Tais resultados corroboram com os resultados da pesquisa de Champangnatte e Nunes (2011). Para os professores entrevistados, a mídia aproxima a escola da realidade dos alunos e também não deixa a escola fora deste mundo tecnológico, até mesmo por ser uma nova forma de linguagem. O vídeo nas aulas foi utilizado como uma ilustração, sensibilização e para motivação de discussão sobre um conteúdo; quanto à internet, os professores a consideraram uma ferramenta que instiga, prende a atenção e favorece a autonomia dos alunos durante a navegação na rede.

Quando se trata de aspectos negativos na utilização desse aparato tecnológico, os professores apontaram igualmente duas realidades: o desinteresse dos alunos pela aula teórica de Educação Física e o não alcance dos objetivos por causa do número reduzido de computadores.

No que concerne à aula teórica, trata-se de uma discussão advinda da reconfiguração da própria Educação Física, a qual, por muito tempo, se restringiu ao saber fazer, concentrando as aulas em atividades ditas práticas. Darido e Rangel (2005) destacam que a resistência dos alunos a uma discussão mais sistematizada dos conteúdos sobre as dimensões conceituais e atitudinais se dá pelo fato de haver uma tradição de que essa disciplina na escola é divertida por resumir-se ao fazer, ao brincar e não ao compreender sentidos e significados do que está sendo abordado.

O outro aspecto negativo relatado diz respeito ao número reduzido de computadores, que inviabiliza atingir os objetivos traçados pelos professores. A falta de estrutura para utilização das TICs na escola é reforçada quando apontada pelos professores como o segundo maior motivo para a não utilização dos laboratórios na escola, como se pode observar na Tabela 2. Tal realidade é constatada em outras cidades como a apresentada em estudo

12 A letra "P" seguida de um número - P.3, P.15, entre outras, referem-se aos professores participantes do estudo. Tal código foi utilizado para preservar a identidade dos respondentes. 
realizado nas escolas municipais de Florianópolis, por exemplo, em que um computador é compartilhado por três ou quatro alunos, o que decerto não colabora para um aprendizado satisfatório (BIANCHI; PIRES; VANZIN, 2008).

Em relação ao não uso do computador, destacam-se as medidas tomadas pela SME referente à convocação dos profissionais que atuavam no LIE e o deslocamento deles para outras escolas ou setores (PMF, 2013), não havendo uma substituição dos mesmos, prejudicando, assim, o ensino e restringindo as atividades. Pode-se verificar a afirmação na seguinte resposta:

"Nem sempre a sala está disponível devido aos agendamentos dos professores da escola. Ultimamente não estamos utilizando a sala de informática, pois não tem profissional na sala para nos atender, com isso encontra-se fechada”. (p.14)

Além disso, os professores ressaltam a falta de conhecimento e apoio para a formação e utilização do laboratório como o terceiro motivo mais apontado para não usarem o computador nas aulas de Educação Física. O conhecimento assim como a formação para a utilização dele no processo de ensino são fatores importantes na inserção das TICs nas aulas, pois, como aponta Sena (2011), não se trata apenas de adaptar a escola tradicional a novos equipamentos ou adaptá-los àquela. É preciso repensar e caminhar para uma proposta que permita transformar o ensino em algo dinâmico, constante e desafiador com o suporte das tecnologias.

Champangnatte e Nunes (2011) apresentam em seu estudo as dificuldades para o uso da internet e do vídeo em sala de aula pelos professores entrevistados: a infraestrutura impede, na maioria das vezes, o uso dessas TICs, pois a sala fica sempre ocupada, os equipamentos são velhos e estragam com facilidade; os professores reclamam da falta de tempo para preparar o material e para frequentar os cursos de capacitação devido às altas cargas horárias de trabalho; muitos não sabem utilizar tais mídias; por fim, os professores sentem falta de um professor responsável pelo laboratório capaz de auxiliá-los nas atividades.

Melo e Branco (2011), por sua vez, encontraram que 41,6\% dos professores entrevistados utilizam tecnologias nas aulas, 33,3\% às vezes e 25,5\% não utilizam. Os professores utilizam mais esses recursos para ensinar o conteúdo do esporte (33\%), depois a dança e os jogos e brincadeiras $(20 \%)$ e, por último, no ensino das ginásticas e das lutas (11\%). A dificuldade mais encontrada por $70 \%$ dos professores é referente à falta de tempo de preparar as aulas, além da motivação e da falta de conhecimento do manuseio dos equipamentos.

Esses autores lembram que muitos dos que atuam, inclusive seus entrevistados, não possuíam contato com as TICs durante sua graduação, tendo aulas expositivas e unidirecionais. Assim, defendem a formação continuada dos professores de Educação Física, bem como reformulação do currículo dos cursos de formação inicial para que esses profissionais possam utilizar as TICs de maneira efetiva nas aulas.

Em relação ao uso das TICs, as escolas ainda carecem de um planejamento mais sólido que envolva a Educação Física e pense desde as mudanças na infraestrutura, para receber esses aparelhos até nas transformações metodológicas para um ensino efetivo. Não há 
dúvidas da importância das TICs em razão do fato de elas estarem presentes no cotidiano da nossa sociedade; porém é preciso haver mudanças, entre elas, a formação de professores.

\section{CONSIDERAÇÕES FINAIS}

O objetivo deste estudo foi verificar com o corpo de professores de Educação Física da rede pública municipal de ensino de Fortaleza a forma pela qual tem se estabelecido o uso das TICs nas aulas deles, no que diz respeito ao uso dos computadores. Diante dos dados, percebe-se que a maioria dos professores raramente utiliza o computador no ensino e, mesmo aqueles que o utilizam, o fazem com pouca frequência no decorrer do ano letivo. $\mathrm{Na}$ realidade dos professores participantes, verifica-se que os principais motivos seriam a falta de profissionais nos laboratórios e de estrutura física adequada para possibilitar a aplicação das atividades.

Além de proporcionar uma melhor estrutura para o trabalho com as TICs, especificamente para com o uso do computador, foco deste estudo, faz-se importante a presença de um responsável pelo espaço informatizado, ou seja, alguém que possa articular os objetivos traçados pelos professores com as possibilidades existentes em meio digital. Nesse processo, é imprescindível que se construa uma proposta pedagógica diferente, a qual aponte para o oferecimento de formação continuada visando a ações mais autônomas, tanto dos professores quanto dos educandos.

Assim, é possível afirmar que as TICs podem contribuir com uma remodelação do processo ensino-aprendizagem, pois as ferramentas tecnológicas oferecem um ensino mais atrativo e real. Para Betti (2010), a sensibilização, a ilustração e o conteúdo de ensino são objetivos que deveriam ser atingidos com o uso das mídias no ensino da Educação Física. Além disso, o autor considera que em uma fase mais avançada é importante que os próprios alunos produzam os textos audiovisuais para aprender a selecionar e construir as informações de maneira clara e objetiva neste tipo de linguagem. Desse modo, "o produto e o processo das mídias devem ser objetos e meios de educação” (p. 139) pelos quais o aluno poderá se apropriar criticamente da cultura corporal de movimento.

Além disso, é importante que o aluno aprenda a captar as informações implícitas e explícitas nas TICs, pense, reflita, crie, signifique, ressignifique e transforme os conhecimentos dele acerca da cultura corporal em qualquer dimensão (conceitual, procedimental ou atitudinal), sem perder a característica do fazer.

Para o uso da TICs, é preciso que o professor se familiarize, conheça e se envolva para encontrar os elementos que podem ser extraídos e quais tecnologias podem auxiliar de fato na aprendizagem dos conteúdos da cultura corporal, contextualizando e desenvolvendo a criticidade por meio da discussão e aproximação do virtual para o real. Além de buscar estimular também a execução das atividades nas aulas e a prática de exercícios fora do período escolar alertando sobre os efeitos do uso exagerado e as consequências aos usuários como, por exemplo, limitação nos movimentos motores, baixa motivação para a prática de atividades físicas e desenvolvimento de doenças hipocinéticas. 
Nesse sentido, faz-se necessário investir na formação dos professores para que os mesmos possam compreender o significado, o sentido e a importância das TICs no processo educativo. A formação dos professores é considerada um fator muito importante para a incorporação efetiva das TICs no ambiente escolar. Segundo Valente (2010), essa formação deve preparar o professor para construir conhecimento, identificar as potencialidades de cada aluno, dominar a área de conhecimento que atua e incluir as TICs em tais processos.

Para Silva (2011), a educação nunca foi prioridade para o governo de nosso país; tudo o que foi feito até agora não contribuiu para melhorar a prática pedagógica e a qualidade de ensino (básico e universitário) com ou sem a tecnologia. Muitos cursos para a formação são de baixo investimento e formam professores de qualidade e remuneração baixas. Assim, para a autora, a única solução é investir no professor (salário, formação e condições de trabalho).

Acredita-se que é preciso que os professores formados ou em formação conheçam muito bem o conteúdo que ensinam e quais objetivos desejam atingir para visualizar como as TICs podem auxiliá-los na construção e ressignificação dos conhecimentos referentes a cada conteúdo.

Assim, o presente estudo pretende alertar os professores de Educação Física para a busca por estratégias de intervenção permeadas pelo uso das TICs nas aulas deles, assim como sugerir para as Instituições de Ensino Superior - IES a inclusão de tal discussão no processo de formação dos futuros professores; mas, talvez, a principal contribuição da pesquisa seja a reflexão sobre a realidade do trabalho com as TICs, no que se refere ao uso do computador, na rede pública municipal de Fortaleza. A partir do exposto, espera-se que os órgãos responsáveis possam traçar caminhos que apontem para uma melhor estruturação do uso dos LIEs na realidade investigada.

Espera-se também que outros trabalhos aprofundem o assunto e oportunizem um maior conhecimento sobre o uso das TICs no universo da Educação Física e que proporcionem inovações, contribuindo e ampliando as possibilidades de intervenção.

\section{REFERÊNCIAS}

BELLONI, Maria Luiza. O que é mídia-educação. 2. ed. Campinas: Autores Associados, 2005. $97 \mathrm{p}$.

BETTI, Mauro. Imagens em avalia-ação: uma pesquisa-ação sobre o uso de matérias televisivas em aulas de Educação Física. Educar em Revista, Curitiba, PR, n. esp. 02, p. 137-152. 2010. Disponível em: < http://goo.gl/1m8cYk>. Acesso em: 15 dez. 2015. ISSN 1984-0411.

BIANCHI, Paula; PIRES, Giovani de Lorenzi. Possibilidades para o ensino-aprendizagem com TICs na Educação Física escolar: uma experiência com blogs. Cadernos de formação RBCE, Campinas, SP, v. 01, n. 02. mar. 2010. Disponível em: 〈 http://goo.gl/nGwbYk>. Acesso em: 07 jul. 2014. ISSN 2175-3962. 
BIANCHI, Paula; PIRES, Giovani de Lorenzi; VANZIN, Tarcízio. As tecnologias de informação e comunicação na rede municipal de ensino de Florianópolis: possibilidades para a educação (física). Linhas, Florianópolis, SC, v. 9, n. 2, p. 56-75. jul./dez. 2008. Disponível em: 〈http://goo.gl/8Lfxa5>. Acesso em: 07 jul. 2014. ISSN 1984-7238.

BRASIL. Ministério da Educação. Secretaria de Educação a Distância. Programa de Formação continuada Mídias na Educação. Integração de Mídias na Educação (Módulo introdutório), Brasília: MEC, 2009. Disponível em: 〈 http://goo.gl/QUZnzt〉. Acesso em: 29 jul. 2014.

BRITO, Maria Aparecida Candine de. Uso dos computadores nos laboratórios de informática educativa na rede estadual de Goiânia: limites e possibilidades do ambiente cyber. In:

SIMPÓSIO DE ESTUDOS E PESQUISAS DA FACULDADE DE EDUCAÇÃO, 19, 2010, Goiânia. Anais eletrônicos... Goiânia: UFG/FE: MEC/CAPES, 2010. Disponível em: < http://goo.gl/rqQdUX $>$. Acesso em: 06 jun. 2014.

BUTRICO, Giovana Moreira; KORSAKAS, Paula. Educação física escolar: perspectivas educacionais da utilização dos meios de comunicação como recurso pedagógico. Revista Mackenzie de Educação Física e Esporte, São Paulo, SP, v. 05, n. 03, p. 39-46. jan./jul. 2006. Disponível em: < http://goo.gl/6Pt2QI>. Acesso em: 14 set. 2015. ISSN 1980-6892.

CAMILO, Rodrigo Cordeiro; BETTI, Mauro. Multiplicação e convergência das mídias: desafios para a Educação Física escolar. Motrivivência, Florianópolis, SC, n. 34, p. 122-135. jun. 2010. Disponível em: < https://goo.gl/hZHBsS >. Acesso em: 14 set. 2015. ISSN 21758042.

CHAMPANGNATTE, Dostoiewski Mariatt de Oliveira; NUNES, Lina Cardoso. A inserção das mídias audiovisuais no contexto escolar. Educação em Revista, Belo Horizonte, MG, v. 27, n. 3, p. 15-38. dez. 2011. Disponível em: 〈http://goo.gl/F1eWCi >. Acesso em: 14 set. 2015. ISSN 0102-4698.

CHANAN, Douglas Santos; NASCIMENTO, Ronaldo José; CHANAN, Aline de Abreu Curunzi. As tecnologias da informação e da comunicação nas aulas de educação física em colégios de ensino médio em Londrina - Paraná - Brasil. 2006. Disponível em: < http://goo.gl/UwRPZk $>$. Acesso em: 26 jan. 2012.

DARIDO, Suraya Cristina. Diferentes concepções sobre o papel da Educação Física na escola. In: UNIVERSIDADE ESTADUAL PAULISTA. Pró-Reitoria de Graduação. Caderno de formação: formação de professores didática geral. São Paulo: Cultura Acadêmica, v. 16, p. 51-75. 2012. Disponível em: 〈 http://goo.gl/0ZgArN〉. Acesso em: 07 jul. 2014.

DARIDO, Suraya Cristina; RANGEL, Irene Conceição Andrade. Educação Física na escola: implicações para a prática pedagógica. Rio de Janeiro: Guanabara Koogan, 2005.

FERREIRA, Aline Fernanda. Os jogos digitais como apoio pedagógico nas aulas de educação física escolar pautadas no currículo do estado de São Paulo. 2014. 127 f. Dissertação (Mestrado em Desenvolvimento Humano e Tecnologias) - Instituto de 
Biociências, Universidade Estadual Paulista, Rio Claro, 2014. Disponível em: < http://goo.gl/LNGvS4>. Acesso em: 14 set. 2015.

FERREIRA, Heraldo Simões; MOTA, Mabelle Maia. A visão dos alunos sobre o uso do facebook como ferramenta de aprendizagem na Educação Física. Revista FSA, Teresina, PI, v. 11, n. 1, p. 188-199. jan./mar. 2014. Disponível em: < http://goo.gl/gsUw4D >. Acesso em: 04 mai. 2014. ISSN 2317-2983.

FORTALEZA. Regionais. Fortaleza, CE, 2014a. Disponível em: 〈http://goo.gl/Yu3cDI $>$. Acesso em: 27 jan. 2014.

FORTALEZA. Secretaria Municipal de Educação. Mapeamento das escolas municipais de Fortaleza. Fortaleza, CE, 2014b. Disponível em: 〈http://goo.gl/E8BmK6>. Acesso em: 07 jul. 2014.

FORTALEZA. Secretaria Municipal de Educação. SME convoca professores de laboratórios de informática e bibliotecas para se lotarem em salas de aula convencionais. Fortaleza, CE. abr. 2013. Disponível em: 〈 http://goo.gl/yXZgoJ $\rangle$. Acesso em: 07 jul. 2014.

GIL, Antônio Carlos. Como elaborar projetos de pesquisa. 4. ed. São Paulo: Atlas, 2002.

MELO, Sergio Correia; BRANCO, Eguimara Selma. O uso das tecnologias de informação e comunicação nas aulas de Educação Física. In: CONGRESSO NACIONAL DE

EDUCAÇÃO-EDUCERE, 5, 2011, Curitiba. Seminário Internacional de Representações Sociais, Subjetividade e Educação-SIRSSE, 1, 2011, Curitiba. Anais eletrônicos... Curitiba: Pontifícia Universidade Católica do Paraná, PR. nov. 2011. Disponível em:

< http://goo.gl/IK8g5k>. Acesso em: 07 jul. 2014.

MIRANDA, Guilhermina Lobato. Limites e possibilidades das TIC na educação. Sísifo Revista de Ciências da Educação, São Paulo, SP, n. 3, p. 41-50. mai./ago. 2007. Disponível em: < http://goo.gl/DEocD5 >. Acesso em: 27 jun. 2014. ISSN 1649-4990.

MORAN, José Manuel. Ensino e aprendizagem inovadores com tecnologias audiovisuais e telemáticas. In: MORAN, José Manuel; MASETTO, Marcos Tarciso; BEHRENS, Marilda Aparecida. Novas tecnologias e mediação pedagógica. 19. ed. Campinas: Papirus, 2011. p. 11- 65.

NASCIMENTO, Karla Angélica Silva; LIMA, Mixilene Sales Santos; FREIRE, Raquel Santiago; CASTRO FILHO, José Aires de. Um olhar sobre as atividades dos laboratórios de informática das escolas municipais de Fortaleza. In: SIMPÓSIO BRASILEIRO DE

INFORMÁTICA NA EDUCAÇÃO, 22, 2011, Aracaju. Workshop de Informática na Escola, 17, 2011, Aracaju. Anais eletrônicos... Aracajú, SE. nov. 2011. Disponível em: <http://goo.gl/eDP63z >. Acesso em: 06 jun. 2014.

OLIVEIRA, Hérica Queiroz. Tecnologias de informação e comunicação na educação e inclusão sócio-digital: uma avaliação do Programa de Informática na Educação PROINFO em Fortaleza. 2011. 141 f. Dissertação (Mestrado em Avaliação de Políticas Públicas) Faculdade de Educação, Universidade Federal do Ceará, Fortaleza, CE, 2011. Disponível em: $<$ http://goo.gl/kTRgkU>. Acesso em: 14 set. 2015. 
PRETTO, Nelson de Luca. Escritos sobre educação, comunicação e cultura. Campinas: Papirus, 2008. 240 p.

SENA, Dianne Cristina Souza de. As tecnologias da informação e da comunicação no ensino da Educação Física escolar. Revista Digital Hipertextus, Recife, PE, n. 6, p. 1-12. ago. 2011. Disponível em: 〈http://goo.gl/X7ZlaI〉. Acesso em: 07 jun. 2014. ISSN 1981-6081.

SILVA, Ângela Carrancho. Educação e tecnologia: entre o discurso e a prática. Ensaio Avaliação e Políticas Públicas em Educação, Rio de Janeiro, RJ, v. 19, n. 72, p. 527-554. jul./set. 2011. Disponível em: < http://goo.gl/UhrQ9o >. Acesso em: 14 set. 2015. ISSN 01044036.

SILVA, Luciana Maria Fernandes. O ensino da capoeira na educação física escolar: blog como apoio pedagógico. 2012. 173 f. Dissertação (Mestre em Desenvolvimento Humano e Tecnologias) - Instituto de Biociências, Universidade Estadual Paulista, Rio Claro, SP, 2012. Disponível em: < http://goo.gl/wHghOK>. Acesso em: 14 set. 2015.

SHIGUTI, Wanderley Akira; SHIGUTI, Valéria da Silva Cruz. Apostila de Estatística. Brasília. 2006. Disponível em: < http://goo.gl/7HzfB4>. Acesso em: 10 nov. 2010.

TERENCE, Ana Cláudia; ESCRIVÃO FILHO, Edmundo. Abordagem quantitativa, qualitativa e a utilização da pesquisa-ação nos estudos organizacionais. In: Encontro Nacional de Engenharia de Produção, 26, 2006, Fortaleza. Anais eletrônicos... Rio de Janeiro, RJ, ABEPRO. 2006. Disponível em: 〈http://goo.gl/clZ75H〉. Acesso em: 07 jun. 2014.

THUMS, Jorge. Acesso à realidade: técnicas de pesquisa e construção do conhecimento. Canoas: EdULBRA, 2003.

VALENTE, José Armando (Org.). Computadores e conhecimento: repensando a educação. Campinas: UNICAMP, 1993. 418 p.

VALENTE, José Armando. As tecnologias digitais e os diferentes letramentos. Pátio, Porto Alegre, RS, v. 11, n. 44, p. 12-15. nov. 2007 - jan. 2008. Disponível em: <https://goo.gl/pKc903 >. Acesso em: 14 set. 2015. ISSN 2179-0248.

VALENTE, José Armando. As tecnologias e a verdadeira inovação. Pátio - Ensino Fundamental, Porto Alegre, RS, v. 14, n. 56, p. 06-09. 2010. Disponível em:

< http://goo.gl/HGQXLa>. Acesso em: 14 set. 2015. ISSN 2179-0248. 


\section{Agradecimentos}

Agradecemos a colaboração de Maria Adriana Borges dos Santos e Raguel Talmay Braga Pinto, membros do Grupo de Estudos em Educação Física Escolar (GEEFE) / UECE, na coleta de dados do presente estudo.

\section{Como citar este documento:}

TORRES, Aline Lima et al. As tecnologias da informação e comunicação e a educação física escolar: a realidade de professores da rede pública municipal de Fortaleza. ETD - Educação Temática Digital, Campinas, SP, v. 18, n. 1, p. 198-214, abr. 2016. ISSN 1676-2592. Disponível em: <http://periodicos.sbu.unicamp.br/ojs/index.php/etd/article/view/8640601>. Acesso em: 05 abr. 2016. doi: 〈http://dx.doi.org/10.20396/etd.v18i1.8640601>. 